\section{Our findings differ}

We congratulate Hudzik and colleagues for their remarkable case of Heyde syndrome $;{ }^{1}$ however, our findings differ substantially. ${ }^{2}$ Our patient presented with relapsing gastrointestinal bleeding, angiodysplasia and severe calcific aortic stenosis and declined valve replacement. We started octreotide to reduce the incidence and severity of bleeding relapses and no new gastrointestinal bleeding was diagnosed over more than two years of follow-up. Currently, the patient has stable hemoglobin at $110 \mathrm{~g} / \mathrm{L}$, despite recent stenting of the right internal carotid artery, chronic renal failure, urothelial carcinoma of the bladder and adenocarcinoma of the neck.

We acknowledge the evidence pointing to Heyde syndrome as an acquired type IIA von Willebrand syndrome, caused by the loss of the largest polymers of von Willebrand factor (vWF) because of the high shear forces generated through the stenotic aortic valve. ${ }^{3}$ Work up in our patient failed to disclose any abnormalities of platelets, coagulation parameters or vWF levels and function, both at presentation and at several points during follow-up after the start of octreotide therapy. We did not perform vWF gel electrophoresis, the gold standard to show the loss of large $\mathrm{vWF}$ polymers. ${ }^{4}$ Despite this limitation, our findings seem to rule out an acquired type IIA von Willebrand syndrome.

We speculate type IIA von Willebrand syndrome could not provide the underlying mechanistic explanation for the association between aortic stenosis, angiodysplasia and gastrointestinal bleeding in some cases of Heyde syndrome. Additional hypotheses should be investigated in this subset of patients.

\section{Giuseppe Famularo MD, Laura}

Gasbarrone MD, Giovanni Minisola MD

Hospitalist Physician (Famularo), San

Camillo Hospital; Internal Medicine

(Gasbarrone, Minisola), San Camillo

Hospital, Rome, Italy

\section{References}

1. Hudzik B, Wilczek K, Gasior M. Heyde syndrome: gastrointestinal bleeding and aortic stenosis. CMAJ 2015 June 29 [Epub ahead of print].
2. Famularo G, Gasbarrone L, Minisola G. Octreotide for Heyde's syndrome: a case report. Presse Med 2014;43:1281-3.

3. Vincentelli A, Susen S, Le Tourneau T, et al Acquired von Willebrand syndrome in aortic stenosis. N Engl J Med 2003;349:343-9.

4. Franchini M, Mannucci PM. Von Willebrand disease-associated angiodysplasia: a few answers, still many questions. Br J Haematol 2013;161:177-82.

CMAJ 2015. DOI:10.1503/cmaj.1150067

\section{The authors respond}

We thank Famularo and colleagues for their comment ${ }^{1}$ on our case report. ${ }^{2}$ As mentioned in the article, currently there is no consensus definition of Heyde syndrome. Despite six decades of study, the construct still raises doubts. Several pathophysiologic mechanisms have been implicated in this condition, but an acquired coagulopathy seems most plausible. Nowadays, many authors affirm that Heyde syndrome refers to a triad of aortic stenosis, acquired type IIA von Willebrand syndrome and recurrent bleeding from gastrointestinal angiodysplasia. ${ }^{3-7}$ Of note, similar observations were made in patients on mechanical circulatory support using pulsatile flow pumps (loss of high molecular weight multimers of von Willebrand factor). ${ }^{8}$ Notwithstanding, pathophysiology of Heyde syndrome is probably multifactorial (mucosal ischemia, cholesterol embolization, acquired platelet dysfunction and inflammatory reactions).

Regarding the laboratory findings, we have to keep in mind that the most plausible cause of Heyde syndrome is the loss of high molecular weight multimers of von Willebrand factor. Not infrequently, this diathesis can only be identified by gel electrophoresis which is the most sensitive assay. ${ }^{9-11}$ Frequently, other tests used in the diagnosis of von Willebrand disease/syndrome turn out normal. ${ }^{9-11}$

Famularo and colleagues ${ }^{1}$ state they ruled out type IIA von Willebrand syndrome, yet they used octreotide - a drug also used in von Willebrand disease/syndrome to control gastrointestinal bleeding. ${ }^{12-15}$

Ultimately, bleeding from angiodysplasia may reflect an interaction between an uncommon coagulopathy (caused by a common valvular disease) and a common vascular disease of the gastrointestinal tract. Notwithstanding, proving the association between aortic stenosis and angiodysplasia remains challenging as both entities are common in older patients.

\section{Bartosz Hudzik MD PhD, Krzysztof} Wilczek MD PhD, Mariusz Gasior MD PhD Third Department of Cardiology, Silesian Centre for Heart Disease, Medical University of Silesia, Zabrze, Poland

\section{References}

1. Famularo G, Gasbarrone L, Minisola G. Our findings differ [letter]. CMAJ 2015;15:1162.

2. Hudzik B, Wilczek K, Gasior M. Heyde syndrome: gastrointestinal bleeding and aortic stenosis. CMAJ 2015 June 29 [Epub ahead of print]

3. Islam S, Cevik C, Islam E, et al. Heyde's syndrome: a critical review of the literature. J Heart Valve Dis 2011;20:366-75

4. Massyn MW, Khan SA. Heyde syndrome: a common diagnosis in older patients with severe aortic stenosis. Age Ageing 2009;38:267-70, discussion 251.

5. Pate GE, Chandavimol M, Naiman SC, et al. Heyde' syndrome: a review. J Heart Valve Dis 2004;13: 701-12.

6. Warkentin TE, Moore JC, Anand SS, et al. Gastrointestinal bleeding, angiodysplasia, cardiovascular disease, and acquired von Willebrand syndrome. Transfus Med Rev 2003;17:272-86.

7. Warkentin TE, Moore JC, Morgan DG. Gastrointestinal angiodysplasia and aortic stenosis. $N$ Engl J Med 2002;347:858-9.

8. Marsano J, Desai J, Chang S, et al. Characteristics of gastrointestinal bleeding after placement of continuous-flow left ventricular assist device: a case series. Dig Dis Sci 2015;60:1859-67.

9. Flood VH. Perils, problems, and progress in laboratory diagnosis of von Willebrand disease. Semin Thromb Hemost 2014;40:41-8.

10. Gadisseur A, Hermans C, Berneman Z, et al. Laboratory diagnosis and molecular classification of von Willebrand disease. Acta Haematol 2009;121: 71-84.

11. Yawn B, Nichols WL, Rick ME. Diagnosis and management of von Willebrand disease: guidelines for primary care. Am Fam Physician 2009;80:1261-8.

12. Franchini M, Mannucci PM. Gastrointestinal angiodysplasia and bleeding in von Willebrand disease. Thromb Haemost 2014;112:427-31.

13. Martin-Grace J, Tamagno G. Somatostatin analogs in the medical management of occult bleeding of the lower digestive tract. Gastroenterol Res Pract 2015;2015:702921.

14. Makris M, Federici AB, Mannucci PM, et al. The natural history of occult or angiodysplastic gastrointestinal bleeding in von Willebrand disease. Haemophilia 2015;21:338-42.

15. Bowers M, McNulty O, Mayne E. Octreotide in the treatment of gastrointestinal bleeding caused by angiodysplasia in two patients with von Willebrand's disease. Br J Haematol 2000;108:524-7.

CMAJ 2015. DOI:10.1503/cmaj.1150068

\section{Letters to the editor}

Letters have been abbreviated for print. See www.cmaj.ca for full versions and competing interests. 